\title{
On the Growth of Ice Crystals in the Air
}

\author{
by \\ K. 章 \\ Mcteorological Research Institute \\ (Received July 14, 1951)
}

Ice Crystals in the Air are grouped into thres fundamental forms, as follows.

a) hexagonal twin-prism,

b) hexagonal prism,

c) hexagonal plate.

Each crystal grows into a skeleton-shaped form, and the hexagonal plate especially shows a beautiful variety observed under the optical microscope. Some examples of these crystals are shown in Figs. 1 and 2
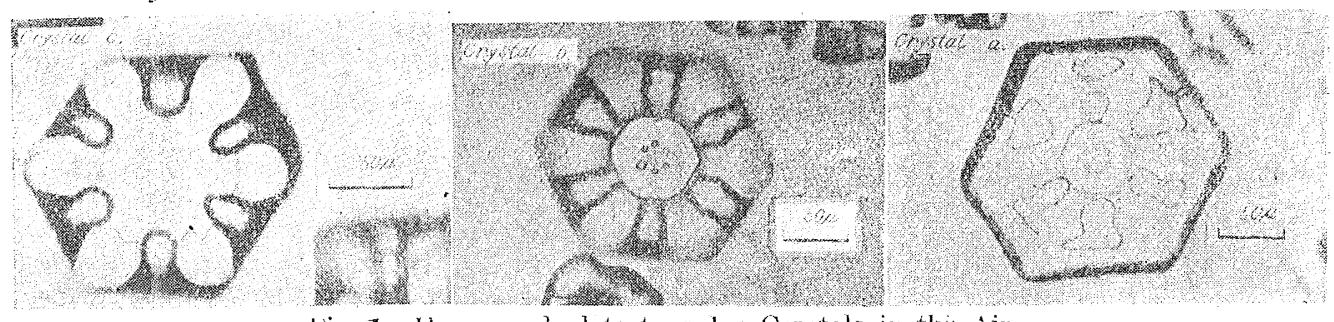

lig. I Hexagonal plate type lee Crystals in the Air
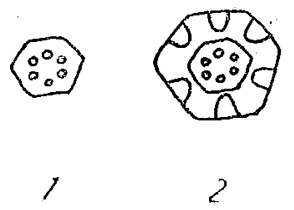

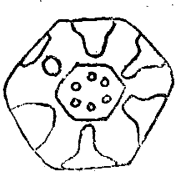

3

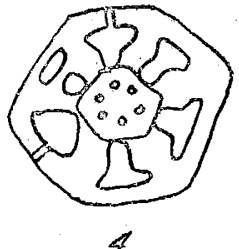

2. 2nd stage,

4. 4th stage.

\section{Crystal a :}

1. Incipient stage,

3. 3rd stage,

Six small bubbles (diameter about $5.5 \mu$ ) are enclc ed in the central part of the crystal in symmetric position. The writer considers the central part which can be definitely distinguished from the surrounding region to be the incipient stage of the Ice Crystals in the Air. From this stage the crystal can grow up step by step as shown in the following various examples.

Table $\mathbf{I}$

\begin{tabular}{cccc}
\hline Stage & Dianeter & Thickness & Volune(ca.) \\
\hline incipient & $58 \mu$ & $58 \mu$ & $1,0 \times 10^{-7} \mathrm{~cm}^{3}$ \\
2nd & $140 \mu$ & $40 \mu$ & $3.4 \times 10^{-6} \mathrm{~cm}^{3}$ \\
$3 \mathrm{rd}$ & $180 \mu$ & $20 \mu$ & $2.8 \times 10^{-6} \mathrm{~cm}^{3}$ \\
4 th & $220 \mu$ & $20 \mu$ & $4.1 \times 10^{-6} \mathrm{~cm}^{3}$
\end{tabular}

In Table 1 , the diameter, the thickness and the size at each stage of growth are shown. From this table, it can be understood that the thickness and the vol- 
umes of each stage can be correlated. It is to be noted that the mutual re ations between the skeletal growth of the crystal and the surface energy of the minute ice and the content of water vapour in the atmosphere are of great importance.

There are two fine tubes which connect the large bubbles and the outer free air (The tube diameter is about $6 \mu$ ). It is probable that the fine tubes are formed in order to keep a balance of air pressure between the interior and the exterior of the crystal. This pressure difference must occur during the winter in the lower layer of the atmospere, for there are frequent inversions of air temperature from about $200 \mathrm{~m}$ to $600 \mathrm{~m}$ in height.

Crystal b:

The incipient stage of this crystal also consists of haxagonl plates of ice and contains six. bubbles in symmetric position. The magnitude of diameter and the thickness at each of the stages are shown in the following table.

Table 2

\begin{tabular}{ccc}
\hline Stage & Diameter & Thickness \\
\hline incipient & $60 \mu$ & $60 \mu$ \\
2 nd & $110 \mu$ & $25 \mu$ \\
$3 \mathrm{rd}$ & $170 \mu$ & $30 \mu$ \\
\hline
\end{tabular}

Crystal c:

It seems that in the incipient stage this crystal is very small but a perfect one. And both the sesond and third stages are distinctly skeleton-shaped crystals.

\section{The Incipient Crystal}

It has been reported that the incipient stage of snow crystals is usually a perfect one with a diameter of about $10 \mu$. As mentioned above the incipient stage of the Ice Crystals in the Air also consists of a perfect or nearly perfect hexagonal crystal. And the crystal forms in the incipient stage are arranged in three groups as indicated in the following table.

Table 3

\begin{tabular}{|c|c|c|}
\hline C'ass & Variety & Diameter Perfectnres \\
\hline $\begin{array}{l}\text { 1) hexagonal skelcton shaped twin-prisin } \\
\text { 2) hexagonal thick plate } \\
\text { 3) hexagonal plate }\end{array}$ & $\underset{E S}{\square}$ & $\begin{array}{l}60 \sim 70 \mu \text { nearly perfect } \\
60 \sim 70 \mu \text { nearly perfect } \\
100 \sim 13.0 \mu \text { pertect }\end{array}$ \\
\hline
\end{tabular}

It is to be noted that the size of the incipient stage of the Ice Crystals in the Air is far larger than that of the snow-cryrtal. The writer can offer no satisfactory explanation for this difference of size. But since the lower atmosphere where the Ice Crystals in the Air are observed is in a very stable and cold condition, it is quite conceivable that they are greater than snow-crystals in the incipient stage,

The Ice Crystals in the Air are grouped roughly into three types as indicated above. The crystals which be ong to b) and c) are in $2 \sim 4$ stages. But it seems that the hex.agonal twin-prism type crystals are almost exclusively incipient ones. This leads to the consideration that the Ice Crystals in the Air betonging to the rexagonal twin-prism type group are formed in the lower laye: of the atmosphere, and the other types of crystals are formed in a layer higher than that. Since the air temperature in cold winter is usually in the condition of inversion, the hexagonal twin-prism type crystal is a naturai consequence. 